since both factors are known to be associated with increased and earlier development. The same factors may therefore be responsible for the accompanying delay in the menopause. Tanner (1962) suggests that the pituitary gland may be involved in both the change in age of menarche and of menopause, and this is made more plausible by the fact that adolescence is not only reached earlier than previously but that boys and girls are also bigger than before.

Since an earlier age of menarche accompanies an earlier and increased development at adolescence it seems possible that a later age of menopause may accompany a delayed or decreased rate of " physiological degeneration"-that is, decreased rate of ageing. The answer to this problem, however, requires further research.

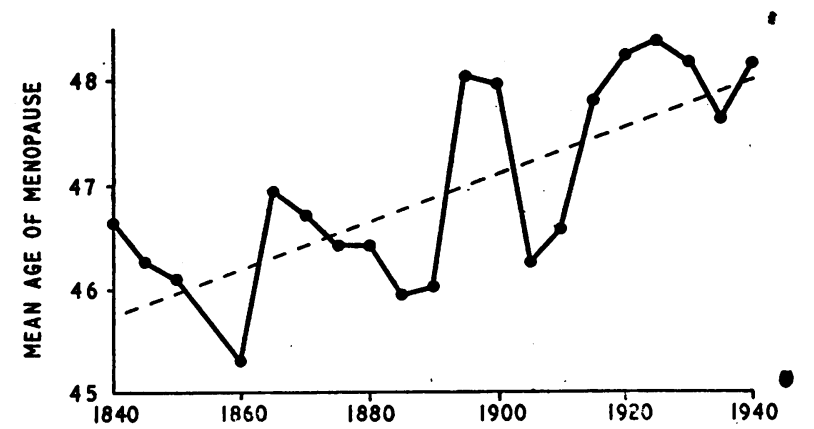

Fig. 2.-Mean age of menopause 1840-1940, compiled from 63 series from European countries. Reproduced from Acta Anatomica, 1948, 4, 456, with the permission of the author, G. Backman, and the publishers, S. Karger, Basle and New York.

\section{Summary}

The modal age and median age of menopause of 443 women from 1951 to 1961 were found to be 50.1 years, using the probit transformation. This represents an increase of about 4 years in the age of menopause compared with that of a hundred years ago. The causes of this delay in the menopause are discussed.

I am grateful to Professor R. E. M. Bowden and Mr. P. R. Norris for their help and encouragement; to Mrs. M. Kerr, of the M.R.C., for statistical advice; to Dr. David Ingram for help in collecting some of the data; and to the Records Department of the Royal Free Hospital.

\section{REFERENCES}

Awon, M. P. (1957). F. Obstet. Gynaec. Brit. Emp., 64, 50.

Backman, G. (1948). Acta Anat. (Basel), 4, 421.

Finney, D. J. (1952). Probit Analysis, 2nd ed. Cambridge Univ. Press, London.

Guy, W. (1845). Med. Tms (Lond.), 12, 363.

Hauser, G. A., et al. (1961). Gynaecologia (Basel); 152, 270.

Medical Women's Federation (1933). Lancet, 1, 106.

Norris, C. C. (1919). Amer. f. Obstet., 79, 767.

Rigden, W. (1870). Trans. obstet. Soc. Lond., 11, 243.

Sanes, K. I. (1918). Trans. Sect. Obstet. Gynec. Abd. Surg. Amer. med.

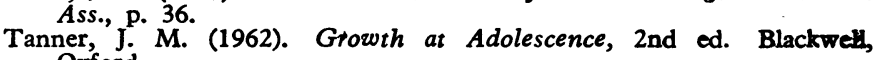
Oxford. Tilt, E. J. (1853). A Change of Life in Health and Disease. Churchin,

Way, S. (1954). 7. Obstet. Gynaec. Brit. Emp., 61, 46.
Wilson, D. C., and Sutherland, I. (1960). Ibid., 67, 320.

\title{
Urinary Gonadotrophins in Post-menopausal Women with Breast Cancer
}

\author{
F. I. R. MARTIN,* M.D., M.R.A.C.P.
}

Brit. med F., 1964, 2, 351-353

The widespread use of hormones and ablative endocrine procedures as palliative measures in metastatic breast cancer has stimulated investigation into possible hormonal abnormalities in this condition. There have been several reports of the excretion of pituitary gonadotrophins in women with metastatic carcinoma of the breast (Segaloff et al., 1951, 1954 ; Loraine et al., 1957 ; Boyland et al., 1958 ; Loraine, 1960), but there is no unanimity regarding their relation to progress or prognosis. The present investigation was undertaken to re-evaluate the prognostic value of the excretion of pituitary gonadotrophins in breast cancer. Studies were made of women with recognized metastases and women with no evidence of recurrence following treatment of the primary tumour.

\section{Methods}

Sixty women attending the follow-up clinic of the Royal Melbourne Hospital were studied. They were selected at random except for the conditions that they were co-operative, were not taking oestrogens, and were either at least three years post-menopausal or had had ovarian ablation performed more than four months previously. Most of the women studied were out-patients, and urine was collected at home and returned

\footnotetext{
* University of Melbourne Department of Medicine, Royal Melbourne Hospital.
}

to the laboratory on the day that the collection ended. Others were studied while in the hospital wards. In 52 women at least two separate 24-hour collections were obtained over a 12 -months period. In the rest only one could be obtained because of death, ill-health, or failure to co-operate.

The urine was collected without preservative, and was refrigerated until extracted by the method of Johnsen (1958). The dried extracts, dissolved in borate buffer, were assayed for total gonadotrophins by the mouse-uterus response at doubling dilutions up to 1 in 100. Results have been expressed as mouse units-1 mouse unit is equal to the reciprocal of the dilution giving a minimal positive response which in this laboratory is equivalent to $0.9 \mathrm{mg}$. H.M.G. 24 or to $0.045 \mathrm{mg}$. N.I.H.H.P.G. Details of the extraction and assay procedures and the variation in the standard responses are described elsewhere (Martin, 1964a, 1964b, 1964c). At the time of assay the details of the patients' clinical state were not known, and on completion of the investigation the case notes of each woman were independently reviewed without knowledge of the gonadotrophin excretion. Age and the duration of the disease from initial diagnosis to the date of the first assay were noted, and on the basis of the clinical records the patients were divided into two groups consisting of those with and those without clinical evidence of distant metastases or local recurrence. The women with known metastases were further classified according to their detailed records as being in "poor" or in "fair" 
clinical condition. Those in fair clinical condition were able to carry out their normal duties and had no evidence of progression of metastases. In addition, an assessment was made whether these women were responsive or non-responsive to administered hormones or ablative endocrine procedures during the period of study. Response was defined as evidence either of objective remission or of subjective relief of pain for a period of at least six months during the study.

Statistical analysis for difference between the groups compared was performed by the use of $\chi^{2}$ tests for heterogeneity and consistent linear trend (Holt, 1948).

\section{Results}

Over the period of 16 months to July 1963166 assays were performed on the 60 women. These comprised 69 assays from 26 women with known metastases and 97 assays from 34 women without evidence of metastases. The mean age of women without metastases was significantly higher than of those with metastases (69 and 53 years respectively), but the mean duration of the disease was similar (5.4 and 5.7 years respectively). The results of assay are expressed as greater than $6.25,12.5,25,50$, or 100 mouse units per 24 hours, or less than 6.25 mouse units per 24 hours (Table I).

TABle I.-Results of 166 Assays on Patients With and Without Known Metastatic Disease. Expressed in Mouse-units per 24 Hours

\begin{tabular}{l|c|c|c|c|c|c|c|c}
\hline & $<6 \cdot 25$ & $6 \cdot 25-12 \cdot 5$ & $12 \cdot 5-25$ & $25-50$ & $50-100$ & $>100$ & Total \\
\cline { 2 - 5 } $\begin{array}{l}\text { No metastases } \\
\text { Metastases }\end{array}$ & 0 & 3 & 4 & 7 & 29 & 54 & 97 \\
\hline
\end{tabular}

Higher dilutions were not assayed routinely, as above 50 mouse units is within the normal range of post-menopausal women for this method both in this laboratory and elsewhere (Johnsen, 1959). The two groups of women with and without metastases. were compared for difference by the chi-square test, assuming a close interval of powers of two and combining the two lowest groups for adequate numbers. The difference was significant: $\chi^{2}=7.064, \mathrm{P}<0.01$.

The results of the 69 assays from the 26 women with metastatic disease are further subdivided as shown in Table II. Using the same method of analysis, the urinary gonadotrophin levels in the groups designated as in fair and in poor clinical condition are significantly different : $\chi^{2}=18.398, \mathrm{P}<0.001$, and the excretion of gonadotrophins in those patients who responded to hormonal manipulation was significantly higher at all levels of assay than those who did not respond: $\chi^{2}=$ 24.67, $\mathrm{P}<0.001$. It will be noted that the hormonal response section of Table II comprises 61 assays from 23 patients, as three patients with metastases were not treated with hormones. The mean age of the women in fair clinical condition and those who responded to hormonal procedures was similar58.4 and 57 years respectively-and was higher than those in poor clinical condition and those who did not respond to hormones-47.8 and 46.8 respectively. Similarly, the average duration of the disease was longer-8.0 and 9.7 years respectively, as compared with 3.5 and 3.7 years in the poor and non-responsive groups.

TABLE II.-Results of Assays on Patients With Known Metastases Classified According to Clinical State and Response to Hormonal Procedures Expressed in Mouse Units per 24 Hours

\begin{tabular}{|c|c|c|c|c|c|c|c|}
\hline & $<6.25$ & $6 \cdot 25-12.5$ & $12.5-25$ & $25-50$ & $50-100$ & $>100$ & Total \\
\hline $\begin{array}{c}\text { Clinical state } \\
\text { Fair } \\
\text { Poor }\end{array}$ & $\begin{array}{l}0 \\
7\end{array}$ & $\begin{array}{l}2 \\
4\end{array}$ & $\begin{array}{l}1 \\
5\end{array}$ & $\begin{array}{l}1 \\
5\end{array}$ & $\begin{array}{r}12 \\
2\end{array}$ & $\begin{array}{r}26 \\
4\end{array}$ & $\begin{array}{l}42 \\
27\end{array}$ \\
\hline $\begin{array}{c}\text { Hormonal re- } \\
\text { sponse : } \\
\text { Response } \\
\text { No response }\end{array}$ & $\begin{array}{l}0 \\
6\end{array}$ & $\begin{array}{l}2 \\
4\end{array}$ & $\frac{2}{3}$ & $\frac{1}{5}$ & $\begin{array}{r}10 \\
2\end{array}$ & $\begin{array}{r}22 \\
4\end{array}$ & $\begin{array}{l}37 \\
24\end{array}$ \\
\hline
\end{tabular}

The close similarity of the results in the two classifications of Table II is explained by the fact that the majority of patients were classified as either "well" and responsive to hormone therapy or as "ill" and non-responsive. The endocrine therapy used included oophorectomy, the administration of androgens, anabolic steroids, and corticosteroids, and the performance of adrenalectomy or hypophysectomy. There was no significant difference in the incidence of the various methods of treatment between the hormally responsive and the nonresponsive groups. None of the extracts assayed was toxic, and the incidence of mouse death during assays in this series was no different from the $1.8 \%$ for all assays performed in the laboratory during the same period.

\section{Comment}

The results indicate that gonadotrophin excretion was lower in those women with carcinoma of the breast who had known metastases than in women apparently free of secondary malignancy. Although the metastatic group was younger than those without metastases, this is not thought to have produced a bias, as gonadotrophin excretion in post-menopausal women appears to decline slightly with age (Johnsen, 1959), and, in addition, no attempt was made to exclude women apparently freetof malignancy but with some other coexisting disease. The smaller group of women with known metastatic disease were found, when considered in more detail, to excrete significantly lower levels of gonadotrophin, both if their clinical condition was poor and if they did not respond to hormonal therapy, as compared with women in relatively good condition who were hormonally responsive.

In seven urine specimens obtained from six women who were both ill and hormonally unresponsive, gonadotrophins were not detectable at the lowest level of assay used. Other assays on these six patients also gave low values of gonadotrophin. Segaloff et al. $(1951,1954)$ were the first to put forward the suggestion that lowered gonadotrophin excretion was associated with a poor response to hormonal therapy. In particular, they found that "pseudo-hypophysectomy," or the absence of detectable gonadotrophins in urine, was associated with a bad prognosis. The Edinburgh group of workers have also published figures which support this view (Loraine, 1960 ; Douglas et al., 1961). They studied the gonadotrophin excretion in women with advanced carcinoma before and after bilateral adrenalectomy and found a higher mean level in those who obtained a remission compared with those who did not. However, this difference was significant only in the group studied after operation.

In contrast, an earlier report from these workers (Loraine et al., 1957) had suggested that the response to oestrogens in post-menopausal women with metastatic carcinoma was worse if urinary gonadotrophins were high; the reason for this discrepancy is obscure. The present investigation is the only one in which a comparable group of women with carcinoma of the breast but without metastases has been studied at the same time as women with secondary malignancy. There was a close similarity between the gonadotrophin excretion in women with hormonally responsive metastases or in fair clinical condition and the group of women without metastases.

The reason for the apparent decrease in gonadotrophin excretion in women with a poor prognosis from metastatic breast cancer is unknown. It may represent a decline in pituitary function, but the recent finding that recovery of added gonadotrophin was less from the urine obtained from hypopituitary individuals who were ill than from urine of those who were in good health (Martin, 1964a) supports the possibility that changes in urinary gonadotrophins may be a non-specific effect of disease. Loraine (1960) mentions this possibility with respect to gonadotrophin excretion in malignancy, and Nabarro (1960) suggested that another index of prognosis in metastatic breast 
cancer, the ratio of etiocholanolone to 17-hydroxysteroids in urine (Bulbrook et al., 1960), could be a non-specific effect of illness. Further, Russfield's (1960) study of the trophic hormone content of pituitary glands at necropsy did not reveal any difference between the pituitaries obtained from individuals who died from malignant disease and those who died from other causes. It is apparent that further investigation of the relation between pituitary gonadotrophin content, urinary excretion, and, if possible, circulating hormone is required before any final conclusion can be reached concerning the basic significance of the present results.

Although low levels of urinary gonadotrophins were, in general, associated with a poor prognosis in this series, their ultimate value as an empirical guide to prognosis after ablative endocrine procedures in women with carcinoma of the breast can be assessed only by prospective studies. Such a study is at present in progress in this department.

\section{Summary}

The results of 166 assays of urinary gonadotrophins in women with carcinoma of the breast are described. There was a significantly lower excretion of gonadotrophins in women who were unresponsive to hormonal therapy and in "poor" clinical condition. The significance of these findings is briefly discussed.

The technical assistance of Miss Pamela Wilson and the help of Sister T. E. Williams, of the Cancer Follow-up Clinic, in supervising the urine collections are gratefully acknowledged, as is the advice of Dr. P. A. Parsons, of the Department of Zoology, University of Melbourne, in the methods of statistical analysis. The honorary medical staff of the Royal Melbourne Hospital kindly gave permission for the study of cases under their care. Standard gonadotrophins, $\mathrm{HMG}_{24}$ and N.I.H.-HPG, were the gifts of the Medical Research Council of Great Britain and the Endocrinology Study Section of the United States National Institutes of Health respectively.

This work was carried out during the tenure of a grant from the Anti-Cancer Council of Victoria.

\section{REFERENCES}

Boyland, E., Godsmark, B., Greening, W. P., Rigby-Jones, P., Stevenson j. J., and Abul-Fadl, M. A. M. (1958). In Endocrine Aspects of Breast Cancer, edited by A. R. Currie, p. 170. Livingstone, Edinburgh.

Bulbrook, R. D., Greenwood, F. C., and Hayward, J. L. (1960). Lancet, 1,1154 .

Douglas, M., Falconer, C. W. A., Strong, J. A., and Loraine, J. A. (1961). In Human Pituitary Gonadotrophins, edited by A. Albert, p. 249. Thomas, Springfield.

Holt, S. B. (1948). Ann. Eugen. (Lond.), 14, 144.

Johnsen, S. G. (1958). Acta endocr. (Kbh.), 28, 69.

Johnsen, (1959). Ibid., 31, 209.

Loraine, J. A. (1960). In Human Pituitary Hormones, edited by G. E. W. Wolstenholme and C. M. O'Connor. Ciba Foundation Colloquia 13, 217. Churchill, London.

Strong, J. A., and Douglas, M. (1957), Lancet, 2, 575.
Martin, F. I. R. (1964a). Aust. Ann. Med., 13, 77.

(1964b). Med. $尹$. Aust. In press.

Nabarro, J. D. N. (1960). Lancet, 1, 1293.

Russfield, A. B. (1960). Cancer, 13,790. J. V., and Murison, P. J. (1954). Ibid., 7, 758. Horwitt, B. N., Schlosser, J. V., and Murison, P. J. (1951). Ibid., 4, 319.
It is said (Roberts, 1959) that the ideal obstetric analgesic should have the following properties : (1) relieve pain ; (2) not cause foetal asphyxia in effective doses; (3) not alter the course of labour; (4) have a reasonably quick disposal to obviate accumulation.

In the search for the ideal drug a clinical trial has been carried out on oxymorphone (Numorphan) (B.M.Y., 1962).

It is claimed that when used in the relief of post-operative pain (Coblentz and Bierman, 1956) and during general anaesthesia (Swerdlow and Brown, 1961) oxymorphone is approximately sixty times as potent as pethidine. Simeckova et al. (1960), in a preliminary report on its use with barbiturates in 100 parturient cases, claimed a high order of potency and a low incidence of side-effects.

Other clinical trials, using supplementary analgesia, have shown oxymorphone to be superior to pethidine in producing greater analgesia (Sentnor et al., 1962) and in shortening the first stage of labour (Snow and Sattenspiel, 1962). However, Sherline and Roddick (1962), also using supplementary analgesia, could demonstrate no significant difference between oxymorphone and pethidine.

Chemistry.-Oxymorphone is a synthetic derivative of morphine chemically identified as 14-hydroxydihydromorphinone hydrochloride. Its synthesis from 14-hydroxydihydrocodeinone was first reported by Weiss (1955). It is mainly detoxicated in the liver, and is excreted as conjugated glucuronate salts, mainly in the urine (Lewenstein, personal communication, 1964).
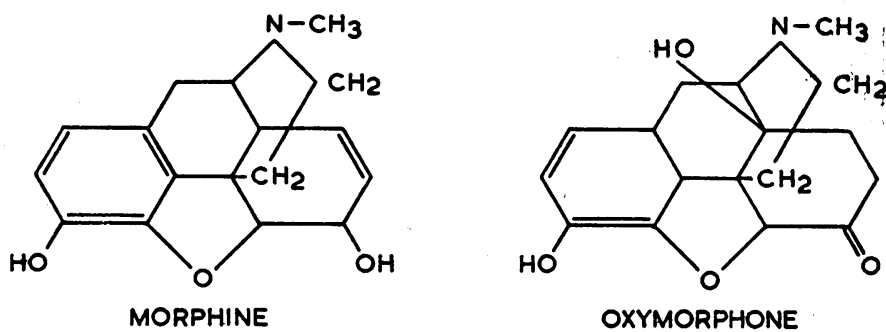

\section{Method:}

A pilot trial of 25 unselected cases in labour was carried out to confirm previous reports that it was an effective and safe analgesic. The drug met both these requirements.

A double blind trial was then carried out, using ampoules containing $1.5 \mathrm{mg}$. oxymorphone in $2 \mathrm{ml}$. saline and $100 \mathrm{mg}$.

* Senior House Officer in Anaesthetics, King's College Hospital. † Senior Registrar in Obstetrics and Gynaecology, King's College Hospital. 